\title{
A Conceptual Framework for a New Nuclear Ethics
}

\section{Vásquez Reyna, Hernán Darío}

2016-07-02

\begin{abstract}
Vásquez Reyna , H D 2016 , ' A Conceptual Framework for a New Nuclear Ethics ' , Peace Review , vol. 28 , no. 3 , pp. 296-301 . https://doi.org/10.1080/10402659.2016.1201942
\end{abstract}

http://hdl.handle.net/10138/234135

https://doi.org/10.1080/10402659.2016.1201942

acceptedVersion

Downloaded from Helda, University of Helsinki institutional repository.

This is an electronic reprint of the original article.

This reprint may differ from the original in pagination and typographic detail.

Please cite the original version. 


\section{TOWARD S A NEW CONCEPTUAL FRAMEWORK FOR A NEW NUCLEAR ETHICS}

Hernán D arío Vásquez Reyna

The assessment of the correct conduct in the pursuit of the good will always be controversial. Nuclear ethics is not free of contradictions in part because discussions in the field were driven by a misleading definition of its object: the atom. Drawing on philosophical realism, this piece argues that, once we understand the causal powers of the atom and subsequently, that the social construction of a nuclear dualism - atomic bombs/ peaceful use of atomic energy - was misleading, then it becomes easier to conclude that a holistic approach to nuclear ethics is more consistent with a project that aims a world without nuclear weapons.

Since last century most international rules and policies treated nuclear weapons and nuclear power (or in general all nuclear materials that were developed from nuclear technology) as if both constituted a dualism. In 1945 Nobel Laureate James Franck already warned of the dangers of nuclear materials but his report, the Franck Report, pointed these dangers as if they were reduced to the possibility that these materials could be used for building nuclear weapons. The 1946 Baruch Plan also grounded the implementation of its policies on the artificial separation of nuclear power for peaceful purposes and atomic weapons. A few years later, when U.S. President D wight Eisenhower proposed his 'atoms for peace' plan at the U.N. G eneral Assembly in 1953, his major concern was to address, as he stated, the atomic danger and power. More specifically, the project was aimed at avoiding the development of more atomic weapons by those who are not the US's friends and allies, amongst them, the Soviet Union. The 'atoms for peace' plan solved the fearful atomic dilemma by reinforcing the dualism. Since then, the opposition atomic bombs vs. peaceful use of atomic energy would be linked to other associations such as peace vs war or good vs. evil, in which good should prevail while evil should be defeated. In the early years of the Atoms for Peace program, nuclear power was seen as the promise of modernity and the solution to mankind's energy problems. Not surprisingly, the promotion of the peaceful uses of nuclear energy was then considered a progressive position, and soon the American project became fruitful. This way the discovery of nuclear fission and the self-sustaining chain reaction not only led to one of the biggest technological developments of the world but also to a new conceptual system. Gradually a new system of concepts was constructed and accepted by or imposed on States through the process of socialization. Scientists, politicians, state representatives amongst many others identified a pattern of differences according to which they differentiate the nuclear status from the rest of the world. Some of the new concepts associate nuclear with the capacity of a state to reach a specific stage of development in nuclear technology, so now we have different expressions that constitute meaning in terms of dualisms. Nuclear states/ non-nuclear states or nuclear weapons states/non-nuclear weapons states are just ways of seeing the world. Nuclear Ethics, or maybe we should call it Nuclear Weapons Ethics, followed the same logic and was devoted to the study of one side of the dualism: the morality of nuclear weapons and deterrence.

Why is the dualism on which most of the policies and practices rely misleading, or at least, inadequate? A few examples, which are not theoretical examples but cases abstracted from the experimental activity of states, blur the socially reconstructed distinction. Let's refer to one side of the dualism, the one related to nuclear weapons in the first place. The cases below will suggest that the possibility of the use of nuclear weapons does not need to be initiated by states in times of war only - as was conceptualized in the Baruch Plan and later in the Atoms for Peace project - but could be initiated by non-state actors, or even if they are initiated by states, this use could be accidental in times of peace. 
a) The first example is mentioned to show the possibility of a terrorist group getting a nuclear weapon or constructing an improvised nuclear device comprised of illegally purchased weaponsusable material to detonate it in a major city: Bin Laden declared in 1998 that it was his duty to obtain Weapons of Mass D estruction. Apparently he understood at this early juncture that using such weapons might become necessary at some stage of his confrontation with the United States and its allies. With this in mind, Al Q aeda feverishly pursued nuclear and biological weapons capabilities before 9/ 11 (Mowatt-Larssen, 2010:38).

b) The second example is presented to show the danger of an accidental use of one of the existing 16,300 nuclear weapons that nuclear states possess today (SIPRI Y earbooks 2010-2014): In 2008 the US Air Force lost track of 6 nuclear weapons- each ten times the size of the Hiroshima bomb- for 36 hours as they flew across the country on a bomber no one realized had live weapons aboard (Cirincione, 2009). More recently, in 2009, a British and a French submarine collided in the Atlantic O cean; together they carried 100 warheads.

Now let's move to the other side of the dualism, the one related to the peaceful uses of atomic energy, to suggest the possibility that installations or nuclear materials originally conceived for a peaceful use, or at least not corresponding to the definition of a nuclear weapon, could (deliberately or not) cause similar effects to those that could be provoked by a nuclear bomb. Within this point the cases of the Three Mile Island (1979), Chernobyl (1986) and Fukushima (2011) are all known but Charles Perrow presents 2 additional events which did not attract much attention: In 1957, a fire in a nuclear reactor at the British plutonium-manufacturing plant at Windscale burned for five days, sending radioactive material over a large area of Cumbria. The event was not made public and no evacuation was ordered. The accident resulted in an estimated 240 cancers among those living near the site. A much more serious accident, also in 1957, was a huge explosion at the Chelyabinsk nuclear weapons processing plant in the eastern Ural Mountains of the Soviet Union. One estimate is that 272,000 people were irradiated; lakes and streams were contaminated, and radioactivity levels were still extremely high in some areas. The world did not know of this event for decades; the Soviet Union thought it was essential to keep it secret. The CIA knew of it immediately but also kept it secret (Perrow, 2013:59-60).

The argument of this piece is that this socially reconstructed distinction of the uses of the atom is misleading since:

a) a state or non-state actor could use, deliberately or not, nuclear material or a facility, originally conceived for a peaceful purpose, to inflict a similar damage to the damage that a bomb could cause, or,

b) in contrast, a State could use a nuclear bomb without the purpose to threaten or to inflict damage.

Accordingly, one could move from one side of the dualism to the other without distinction.

In relation to a), terrorists could attack a nuclear facility in hopes of causing a large release of radioactivity - similar to how they used airplanes on 9/ 11 as an inscrutable weapon. In fact, there is evidence that Al Q aeda's leadership considered such a possibility before 9/11, when their operatives reportedly conducted some slight investigation of U.S. nuclear reactor facilities. But thanks to enhanced security and reinforced defences at U.S. nuclear sites, the available intelligence seems to indicate that Al Q aeda had concluded that it was too difficult to either (1) crash a plane into a nuclear facility or (2) use a team to penetrate a nuclear facility to gain access to nuclear weapons and materials (Mowatt-Larssen, 2010:43).

In relation to $b$ ), the practice of some States confirms the fact that they allow the transit and temporary visits of nuclear delivery vehicles, including so called "innocent passage", in the belief that they do not affect their security when they are subject to certain restrictions. This is the case of Russian warships - the naval squadron led by the nuclear-powered cruiser Peter the Great - 
that approached Venezuela's Caribbean coast to coincide with President D mitry Medvedev's visit to Caracas in 2008.

Cases a) and b) bring to this discussion the question whether a conceptual system that divides the applications of the atom according to the purpose of their use could consistently serve as conceptual framework of a project that aims at the elimination of all nuclear weapons. This piece suggests that it is not.

Most of these contradictions have already been known since last century: that the facilities that enrich uranium to low levels for fuel could be used to enrich uranium to high levels for nuclear bombs; that the facilities that reprocess spent reactor fuel rods for disposal could be used to extract plutonium for nuclear weapons, that nuclear power plants producelow-grade plutonium that could be reprocessed into weapon-grade plutonium. The representative for Ethiopia, Mr. Zelleke, speaking at the meeting of the UN Eighteen Nation Disarmament Committee held on 50 ctober 1967, put this very clear: '... we are convinced of the fact, and so far it has not been challenged, that the technology required for the production of peaceful nuclear explosive devices is the same as that required for nuclear weapons, and also that the same peaceful devices can serve to wage a war with a consequential devastation equal in magnitude to that of nuclear weapons'. Accordingly, it is not new information that the reconstruction of the dualism, atomic bombs vs. peaceful use of atomic energy, was misleading. But what it is more important for our argument is that, leaving aside the reasons for its reconstruction and socialization, its persistence is still negatively affecting our understanding of the world. Y et, in so far as our actions are guided by those ideas, we now need to be critical of them.

What, then, was the mistake? Intrinsically, atomic reactions are neither good nor bad, rational nor irrational, although we may say they are good or bad for us, in relation to our own schemes (Sayer, 41). A tomic reactions possess some internal properties that have powers which when activated can produce harm to human beings and the environment but, despite the existence of these properties, as a non-social object, the atom does not include concepts or meanings. We, subjects, attach those meanings to them and that is what actors did last century although inadequately. The problem was that they attributed the harmful properties to nuclear weapons when the properties existed but at a different stratum of reality. The causal powers pre-exist nuclear weapons and correspond to a different object: the atom. Nuclear weapons are just one of the applications of the atom amongst many others. This explains why for example, different types of reactors have different levels of proliferation resistance, but no matter how they are badged, all nuclear fuels and all nuclear products can be utilized in a dirty bomb, if not a nuclear bomb (Abbott, 2012:26). Similarly, all applications of atomic reactions can be used for good or evil, in the same way that a knife can be used for peaceful or non-peaceful purposes. It is clear now that defining a non-social object 'peaceful nuclear energy' does not make the object more peaceful and separating knives in two groups according to the purpose of their use would be equally misleading.

The apparent lack of knowledge developed on the negative effects of nuclear radiation, emitted by both bombs and power plants alike, does not destroy our argument against the dualism. Uncertainties about the extent of the negative effects of the radiation of power plants and weapons should not serve as a basis for the argument that they will not produce harm to humans since, ontologically, the world exists independently of our knowledge of it. Since last century we have been witnesses of the destructive effects of nuclear bombs. At the time of 'the Shrimp', the largest U.S bomb ever, was tested in 1954, it was difficult to anticipate it was going to have a yield of 15 megatons which is 2.5 times higher than expected. At the time of the publication of the Franck Report it was very unlikely that James Franck considered that terrorists would be planning to possess nuclear material 50 years later; because humans never had all knowledge of the natural world and because in an open system such as our social world it is extremely difficult if not 
impossible to predict. What seems to be wrong is to accept that, because we do not have enough knowledge of the negative effects of radiation, we should close our analysis to other possibilities as if we had that knowledge and those predictive powers. If there has not been a nuclear war, it does not mean that there will never be one. If O sama Bin Laden is not alive it does not mean that no other terrorist will succeed in obtaining nuclear material. If we did not witness an accident when Russian warships neared Venezuela's Caribbean coast in 2008, it does not mean that a British warship could not cause one in a Peruvian port. So if we haven't witnessed a nuclear plant accident that could have killed the same number of people as the Hiroshima bomb did, we cannot conclude that in 50 years time a nuclear plant much bigger than the current biggest plant on earth could cause the same number of victims.

Unfortunately, what is inadequate for the lens of Philosophical Realism, seems to be reified by the literature of Nuclear Ethics. Since its inception, the Nuclear Ethics literature has been primarily concerned with the morality of nuclear warfare and deterrence (D oyle, 2010:92)(2). Philosophical approaches to nuclear ethics have varied along the consequentialist-deontological spectrum and from these two lenses they address making war and deterrence as the main if not only topics for moral scrutiny. Since then it has also been considered an interdisciplinary field at the intersection of international security studies, the broader field of international relations, and (applied) ethical theory (D oyle, 2010:288)(1). D uring the cold war, realists criticized Kantian nuclear abolitionism as too idealistic, while Kantians criticized nuclear deterrence institutions as morally incoherent. Not surprisingly, in a geo-historical context where nuclear accidents were played down by nuclear powers, moral arguments against the use of deterrence were limited to the destructiveness of nuclear weapons by its intentional use.

For a world without nuclear weapons, a new ethical framework should replace this inconsistent conceptual system that currently opposes nuclear bombs to peaceful nuclear energy because just as it is morally wrong to harm humans or the environment with a nuclear bomb, it is morally wrong to harm humans or the environment with nuclear waste or with an inscrutable weapon in a nuclear power plant. Just as it is morally wrong to harm humans with a nuclear bomb in time of war, it would be morally wrong to harm humans or the environment, even unintentionally, in a port visit in time of peace. This explains our proposal to construct a new nuclear ethics that treats the issue as a whole: A broader conception of nuclear ethics that addresses the moral dimension of the applications of the "atom", for the "risk of harm" it imposes not only on "humans" but also on "the environment", no matter if it is "in time of war or peace", constitutes a more consistent argument in favour of a world without nuclear weapons than one that limits the discussion to the ethics of nuclear weapons in warfare and deterrence alone.

\section{Recommended Readings}

- $\quad$ Abbott, D erek. 2012. "Limits to growth: Can nuclear power supply the world's needs?" Bulletin of the A tomic Scientists 68(5):23.

- Archer, Margaret et al. (Eds.) 1998. Critical Realism, Essential Readings. London: Routledge.

- $\quad$ Bhaskar, Roy. 1986. Scientific Realism and Human Emancipation. London: Verso.

- Bhaskar, Roy. 1979. The Possibility of Naturalism, a Philosophical Critique of the Contemporary Human Sciences. Sussex: The Harvester Press.

- Cirincione, Joseph. 2009. The Open Window for Transformation. Available at: http:/ / ploughshares.org/ content/ us-nuclear-policy-open-window-transformation, last accessed March 22, 2016.

- $\quad$ D oyle II, Thomas E. 2010 (1). "Reviving Nuclear Ethics: A Renewed Research Agenda for the Twenty-First Century", E thics \& International A ffairs 24(3): 287. 
- Doyle II, Thomas E. 2010 (2). "Kantian non-ideal theory and nuclear proliferation" International Theory 2(1): 87.

- D Duyeon, Kim and Jungmin Kang. 2012. "Where nuclear safety and security meet”, Bulletin of the A tomic Scientists 68(1): 86.

- Lee, Steven. 1985. "The Morality of Nuclear Deterrence: Hostage Holding and Consequences", E thics 95(3): 549.

- McMahan, Jeff. 1985. "D eterrence and D eontology", E thics 95(3): 517.

- Mowatt-Larssen, Rolf. 2010. "Nightmares of Nuclear Terrorism". Bulletin of the A tomic Scientists (March/ April): 37.

- $\quad$ Perrow, Charles. 2011. "Fukushima and the inevitability of accidents". Bulletin of the A tomic Scientists. 67(6): 44.

- Perrow, Charles. 2013. "Nuclear denial: From Hiroshima to Fukushima". Bulletin of the A tomic Scientists, 69(5): 56.

- $\quad$ Sayer, Andrew. 1992. M ethod in Social Scieno, a Realist A pproach. Second Edition. London \& New York: Routledge.

Hernán Darío Vásquez Reyna, LL.M (Nottingham), PhD Candidate (Helsinki), is Researcher at the Department of Economics and Political Studies of the University of Helsinki and Council member of the International Peace Research Association (IPRA). 